\title{
Populismo en Chile: Las vías no tomadas y la incidencia de la cultura política del país.
}

\author{
Populism in Chile: The pathways non taken and \\ the incidence of the political culture in the country
}

NICOLÁS BRAVO REYES

Pontificia Universidad Católica,Chile ${ }^{1}$

RECEPCIÓN: 28/ 09/2016 • ACEPTACIÓN: 27/ 12/ 2016

RESUMEN Dentro de Latinoamérica, se suele situar a Chile como un caso excepcional donde no han existido grandes líderes populistas. El siguiente trabajo investiga por qué ocurre esta excepcionalidad indagando primero, a nivel histórico, eventuales liderazgos populistas como Carlos Ibáñez, para luego investigar la causa de por qué ninguno de estos líderes chilenos dejó un legado significativo que influya en la política nacional actual, a diferencia de lo que sí ocurrió, por ejemplo, con el Peronismo en Argentina. Como respuesta se presenta un análisis de coyunturas críticas y "caminos no tomados" que dieron como resultado un país sin grandes liderazgos populistas, situación que se explicaría por la existencia de una cultura política caracterizada como "institucionalista" y que es hostil al populismo.

PALABRAS CLAVE Populismo - Chile - Cultura política - Institucionalismo Historia

ABSTRACT In Latin America, it is customary to place Chile as an exceptional case where not important populist leaders really existed. The aim of this work is to dig into this exceptionality. First, by inquiring, in a historical level, the existence of eventual populist leaderships like Carlos Ibañez, for then scrutinize

1. Cientista Político, Pontifica Universidad Católica, Chile. Coordinador de Contenidos Fundación Chile Descentralizado. Correo: nnbravo@uc.cl 
the historical roots of why nobody of these Chileans leaders reached a significant legacy in current national politics, unlike what happened for example, with Peronism in Argentina. As a plausible answer it will show an analysis of the critical junctures and explore the "non taken pathways" that produce as result a country without important populist leaderships. The main result of this work is that this situation is explained by the "institutionalist" Chilean political culture, hostile to populism emergence.

KEYWORDS Populism - Chile - Political culture -institutionalism - history

\section{INTRODUCCIÓN}

Las auspiciosas primeras décadas que vivió Chile luego de recuperar sus sistema democrático mediante una alta participación electoral en el plebiscito de 1988, donde se logró reducir la pobreza y alcanzar estabilidad política institucional, se han visto enjuiciadas en los últimos años por un creciente desprestigio de la clase política y partidos tradicionales que se ha expresado en una sostenida disminución de la participación electoral (Contreras y Navia, 2013; Contreras y Morales, 2014), en paralelo con un fuerte aumento y presencia de movimientos sociales de diversa índole (Ramírez y Bravo, 2014).

Dicha situación de desprestigio de la clase política resulta proclive a la emergencia de liderazgos populistas, tal como ocurrió con el surgimiento de Hugo Chávez en Venezuela (Villa, 2005), pero en Chile aún predominan liderazgos "institucionales" ligados a las dos grandes coaliciones de centroizquierda y centroderecha que han coexistido en las últimas décadas. ¿Por qué no ha surgido un liderazgo populista rupturista como el de un Perón o Chávez en Chile? La explicación la encontramos en los diversos critical junctures (coyunturas críticas), es decir momentos históricos donde líderes políticos tomaron caminos que no fueron favorables para fortalecer un liderazgo populista como sí ocurrió en otros países. 


\section{MARCO TEÓRICO}

\section{¿Qué entendemos por populismo?}

Para continuar con el estudio es necesario dilucidar qué entendemos por "populismo", concepto polémico dentro de las ciencias sociales. Por ello, se realizará un primer acercamiento al concepto a través de tres enfoques. En primer lugar, tenemos el enfoque "Socio Cultural" que define al populismo como un estilo político asociado a lo popular, que se traduce una acción performativa del líder y de seducción con sus seguidores. Considerando la identificación del estilo político del líder populista con la idiosincrasia de los sectores populares (Knight, 1998), es que se crea la dicotomía de lo "bajo" y lo "alto" de acuerdo a la tipología de Pierre Ostiguy (2013). Relacionado a lo anterior existe un enfoque "Discursivo" (Laclau ,2005; Panizza, 2005; Mudde y Rovira, 2012) que ve al populismo como una ideología "delgada" basada en el maniqueísmo y antagonismo donde los líderes populistas representan al pueblo, y quienes se oponen a lo que quiere el pueblo constituye el "enemigo", crenado de paso una dualidad entre el bien (pueblo) y el mal (no pueblo). La dualidad entre lo "bajo" y lo "alto" es coincidente con el maniqueísmo entre el pueblo y no pueblo (De la Torre, 1992: 396). Existe también un enfoque "Institucionalista", que ve al populismo como una estrategia de poder personalista y por consiguiente anti institucionalista. Autores que se enmarcan en este enfoque como Weyland (2001) creen que el populismo responde a una estrategia política por la cual el líder personalista intenta conseguir o ejercer el poder de gobierno basado en un apoyo no institucionalizado, no mediado, directo de parte de un gran número de seguidores mayormente no organizados.

En adición, existen autores que clasifican a los regímenes populistas de acuerdo a su ubicación temporal (De la Torre y Arnson, 2013) donde encontramos tres períodos históricos, siendo el primero el de "populismos clásicos" entre las décadas de 1930 a 1950, que se asociaron a la incorporación política de trabajadores y a la par de procesos industrializadores y donde en este período se encuentran líderes populistas como Juan Domingo Perón. Luego se encuentran los "neopopulismos" en la década de 1990's asociados a las reformas económicas "neoliberales" con líderes como Carlos Menem; y finalmente están los "populismos radicales" asociados a políticas de izquierda a partir del 2000's, donde destacan líderes como Hugo Chávez.

En relación a todo lo anterior es que para efectos del trabajo identificamos los liderazgos populistas con características personalistas y anti institucional, identificado con "sectores populares" (el pueblo), maniqueo en cuanto el populismo crea la dicotomía pueblo/ no pueblo, ecléctico en términos político-ideológico, y 
movilizador ya que busca de modo constante demostrar que posee un apoyo sustancial.

\section{Cultura política}

La "cultura política" es el otro concepto a considerar para el trabajo. De acuerdo al concepto de Almond (1965), se entiende como el énfasis en la importancia de los valores, sentimientos y creencias en la explicación del comportamiento político en un determinado lugar. Asimismo, existen dos grandes teorías sobre la formación de una cultura política: verla como un fenómeno esencialista o como un fenómeno cambiante. A la primera teoría adscriben autores como Howard Wiarda (2001), quien sostiene la idea de que la cultura política es determinada por su origen en un pasado lejano, es decir, en una etapa inicial de desarrollo histórico en una sociedad o nación. Por otro lado, la segunda teoría sostiene que los valores originarios expresados en la primera teoría son susceptibles de cambios asociados a eventos importantes, conmovedores y traumáticos que dejan huellas en los pensamientos y las actitudes de la gente de un país, a juicio de Tomás Moulián (1995).

En el caso de Chile se sostiene que su cultura política se caracteriza principalmente por el respeto al orden y el apego a las leyes (Scheele, 2010), características que se basa en antecedentes históricos que muestran una configuración institucional que supo ser estable e impersonal en los liderazgos presidenciales a diferencia del caudillismo y la inestabilidad de otros países de América en el siglo XIX. Estos valores que son hostiles al populismo se refuerzan con especial fuerza a partir del traumático evento que significó el golpe de Estado de 1973 y los posteriores 17 años de dictadura militar, que tuvo como sello reinstaurar el orden y el respeto a la institucionalidad que Chile había perdido con el Gobierno de Allende, a juicio de los militares y ciertos sectores sociales que apoyaron este golpe de Estado (Garcés y Rodríguez, 2004: 121).

\section{ANÁLISIS HISTÓRICO COMPARATIVO}

\section{LOS CAMINOS “POPULISTAS” NO TOMADOS EN CHILE}

\section{La primera piedra: Arturo Alessandri y su supuesto "populismo"}

La problemática de la "cuestión social" presente en la sociedad chilena del siglo XX, asociada a las paupérrimas condiciones de vida que tenía el sector obrero, sumado a su rápida organización, generó preocupación entre la elite 
gobernante y esta situación explica el contexto en que llega al poder Arturo Alessandri en 1920, el primer caso en Chile que suele ser catalogado como populista.

Las características discursivas de Alessandri tuvieron claros componentes populistas tanto en su campaña para llegar a La Moneda como en su período presidencial, lo cual queda de manifiesto en discursos como el dado en Talcahuano en 1923: "Bajé hasta el pueblo, sentí sus dolores, sufrí y me impresioné con ello, me juré a mí mismo la resolución inquebrantable de servir a las aspiraciones y derechos del pueblo. Este país había sido gobernando por una casta dirigente, y tomaban participación sólo unos cuantos ciudadanos". (Hawkins y Rovira, 2013: 13). En el mismo discurso Alessandri afirmaba que su Gobierno democrático sería "por el pueblo y para el pueblo". Este ejemplo de discurso de Alessandri expresa claros elementos populistas. En primer lugar se encuentra la relación líder-pueblo, en donde el primero se muestra como un salvador de las desgracias y males del segundo, que es capaz de sentir este sufrimiento. Luego viene el ataque al establishment que representaba los sectores opositores a las políticas de Alessandri, y finalmente en el discurso el "León de Tarapacá" (apodo que se le dio a Alessandri) señala que su gobierno es por y para el pueblo, apelación característica al pueblo por parte de los regímenes populistas.

Una vez que Alessandri llega a La Moneda y considerando los antecedentes "populistas" que presentó como candidato aparece un critical juncture referente al modo en que va gobernar e implementar sus medidas sociales: Una vía institucional, o una vía "populista" mediante movilización de masas. Sorpresivamente Alessandri toma la vía institucional tratando de llevar a cabo sus reformas de manera institucional como lo hicieron presidentes de la época como Batlle y Ordóñez en Uruguay e Yrigoyen Argentina. Esta decisión resulta muy significativa en cuanto se contrapone a una de las características de los populismos: la movilización social como apoyo al régimen. A diferencia de tratar de cooptar al movimiento obrero tal como lo hizo luego Perón en Argentina, Alessandri no contó con una relación tan fluida con la clase trabajadora al tener episodios de represión de las protestas sociales lideradas por las organizaciones obreras (Mellado, 2015), lo que hizo que perdiera una potencial base de apoyo movilizada para un liderazgo populista. Otra vía no tomada por Alessandri fue un eventual apoyo en los militares. Existía un grupo importante de militares (como Carlos Ibáñez y Marmaduque Grove) que compartía muchas de las ideas reformistas y modernizadoras que presentaba el proyecto de Alessandri.

En suma, la apuesta por la vía "institucional" del "León" no fue exitosa, ya que su coalición de apoyo "Alianza Liberal" no contó con mayoría en el Congreso, y cuando la tuvo, divisiones internas impidieron un apoyo pleno al proyecto de Alessandri. Este fracaso del "León” al tomar la vía institucional para 
implementar sus medidas sociales será fundamental para entender el surgimiento de Carlos Ibáñez del Campo como eventual liderazgo populista. Además, el Alessandri de 1920 que llegó al poder con un discurso populista combinado con reformas sociales tuvo un giro radical cuando es electo nuevamente Presidente de la República en 1932, donde su principal característica fue la de reestablecer el orden por medio de un gobierno civil ante el caos imperante y la inusual participación de las Fuerzas Armadas en política desde 1924.

\section{¿Fue el primer gobierno de Ibáñez populista? Los caminos no tomados.}

Las reformas sociales impulsadas por Arturo Alessandri solo pudieron lograrse una vez que los militares irrumpieron en política, ya sea presionando al Congreso durante el "Ruido de Sables" en 1924, como también una vez que Carlos Ibáñez asume de manera total el poder en 1927.

La combinación personalista de Ibáñez más beneficios sociales podría haber derivado en un claro caso de populismo. Sin embargo, a pesar de la creación de un grupo de apoyo denominado "Confederación Republicana de Acción Cívica" (CRAC), esto no fue suficiente para lograr traspasar el apoyo del sector obrero de manera total hacia su figura, como sí ocurrió con grandes organizaciones de trabajadores como la "Confederación General del Trabajo" (CGT) en Argentina que funcionó como sostén obrero del liderazgo populista de Perón. Por otro lado, el nivel de movilizaciones de apoyo hacia su gobierno existió, pero fue limitado dado a que uno de los principales objetivos de Ibáñez fue la mantención del orden social. En ese sentido, a pesar de que se mostraba crítico hacia la elite, en los hechos durante su mandato esta relación fue más bien amistosa, a diferencia de la conflictiva relación que tuvo en sus inicios Perón y las elites argentinas. Esto llevo a que las apelaciones al pueblo y el discurso maniqueo de Ibáñez en este período es escaso tal como lo reporta Hawkins y Rovira (2013). Acorde a lo señalado por los Colliers (2002) no toda incorporación es populista, siendo precisamente Ibáñez un ejemplo de ello ya que no crea un partido de masas (la CRAC no tuvo relevancia política) ni genera un vínculo con el mundo sindical obrero del tipo de la CGT con Perón. En ese sentido, el primer gobierno de Ibáñez se quedó a "medio camino" para calificar dentro de la tipología populista de los Colliers en el contexto de los primeros populismos latinoamericanos surgidos en la primera mitad del siglo XX.

Finalmente, desde el enfoque de populista socio-cultural de estilo, es evidente el contraste que existe entre Ibáñez, en su primer período, con lo que fue un caso de populismo clásico como la irrupción de Perón y Evita en Argentina. Por ejemplo, mientras el Peronismo atacaba fuertemente símbolos de la oligarquía 
como las universidades, Ibáñez buscaba fortalecerlas. Esta actitud de Ibáñez deja al descubierto otro aspecto más que lo aleja de una tipología populista dentro de su primer gobierno, ya que no rechazaba símbolos asociados a lo "alto" (Ostiguy, 2013) como sí lo hizo claramente el Peronismo con las universidades en sus inicios. En efecto, las características de Ibáñez fueron más "autoritariasdesarrollistas" del tipo de Getulio Vargas en Brasil durante su primer período entre 1930 y 1945.

\section{Los orígenes "populistas" del socialismo chileno y su caudillo: Marmaduque Grove}

En los agitados días finales de la "República Parlamentaria” (1891-1925), dentro del grupo militar disconforme con la ineptitud política del establishment para responder las demandas sociales, Carlos Ibáñez no sería el único caudillo militar que intentaría instaurar un proyecto con rasgos populistas. Existió otro caudillo militar llamado Marmaduque Grove, quien compartía los planteamientos políticos de Alessandri en cuanto a la búsqueda de una mayor justicia social en el país. La "conversión" de Grove al socialismo tiene ribetes anecdóticos (Drake, 1992:57), ya que la noche anterior a la rebelión armada que llevaría a cabo fue convencido que la solución que el país necesitaba era un "Estado socialista”. Este curioso evento de "conversión" de Grove al socialismo representa de modo simbólico una primera característica populista del caso de Grove y el socialismo: su eclecticismo y ambigüedad ideológica respecto al concepto teórico político.

Un segundo elemento importante en el populismo presentado por el socialismo chileno en sus orígenes bajo Grove fue la gran relevancia que él adquirió como líder caudillista. Tal como ocurre con los líderes populistas, Grove fue presentado por sus seguidores como una figura mesiánica redentora comparable con Cristo que mediante el socialismo solucionaría los problemas país, especialmente los de los sectores populares. El liderazgo de Grove sumado a la popularidad que ganó en la breve República Socialista (duró 12 días, entre el 4 y 16 de junio de 1932) lo perfiló como la cara visible del naciente socialismo en Chile y de su partido, y es por ello que fue candidato en la elección presidencial de octubre de 1932 pese a que se encontraba exiliado en Isla de Pascua, por lo que no pudo hacer campaña personalmente afectando evidentemente su potencial liderazgo populista. De hecho, Grove arriba al continente el mismo día de la elección. A pesar de estas dificultades obtuvo un 17,91\% de los votos siendo la segunda mayoría, desplazando a los candidatos de los tradicionales partidos Liberal y Conservador, pero lejos del 55,31 \% de Arturo Alessandri. 
Las causas de la rápida caída de la República Socialista se deben a una serie de factores entre los que se encuentran las divisiones dentro de la Junta Militar que lideró dicho gobierno, sumado a la oposición de la elites nacionales y grupos económicos extranjeros que vieron al proyecto socialista como una amenaza a sus intereses. Un tercer elemento relacionado con la falta de organización por parte de los adherentes de Grove en su aventura socialista también es determinante para entender su corta duración. A pesar de que existieron protestas sociales en contra del derrocamiento de la República Socialista, estas movilizaciones no fueron lo suficientemente poderosas como para revertir la caída y exilio de Grove, ya que a su vez hubo una fuerte represión por parte del gobierno "golpista" de Carlos Dávila.

Finalmente, la estrategia "legalista" que tuvo el Partido Socialista (PS) en su fundación en 1933 determinó su futuro como nueva fuerza política representante de sectores medios y bajos. La entrada del PS de lleno a la política partidista sería un punto sin retorno a sus orígenes populistas, ya que se abandonaron vías personalistas como las utilizadas por Grove, dando paso a una mayor institucionalización del partido.

\section{Ibáñez vuelve: La transformación del dictador en demócrata (1937-1958)}

Exiliado en Argentina producto de su tormentosa caída azuzada por las graves consecuencias económicas de la Gran Depresión de 1929, Ibáñez se ausentó de la política nacional entre 1931 y 1937, para luego volver a Chile aspirando a ocupar nuevamente la presidencia del país. El desplazamiento de Ibáñez desde la izquierda a la derecha pasando por el centro de manera pragmática desde 1937 a 1952 es una primera señal del carácter oportunista propio de los populismos que presenta Ibáñez al carecer de una posición política clara y definida en ese aspecto.

Dado el giro a la derecha que tuvo el segundo gobierno de Arturo Alessandri, en las elecciones de 1938 Ibáñez intentó realizar alianzas con sectores ligados a la izquierda en miras de enfrentar al candidato oficialista, Gustavo Ross. De hecho, Ibáñez se consideraba como una víctima de la oligarquía que conspiró para derrocar su primer gobierno que tuvo grandes realizaciones populares. Los principales ejes de esta campaña fueron justicia social, nacionalismo, y la crítica a la oligarquía y al capitalismo.

Sumado a los tres elementos mencionados anteriormente, Ibáñez añadió dos aspectos claramente populistas en su campaña de 1938: Mesianismo y contacto directo con sectores populares mediante grandes concentraciones, estrategia que Perón ocuparía unos años más tarde. El elemento mesiánico se 
expresó en mostrar a la candidatura de Ibáñez como "una marcha irresistible hacia la salvación de Chile". Por último, el elemento movilizador y de contacto directo con las masas fue prácticamente obligatorio para Ibáñez debido a que los sindicatos estaban dominados en su gran mayoría por corrientes comunistas y socialistas que apoyaban al candidato del Frente Popular Pedro Aguirre Cerda.

La derrota de Ibáñez en la elección presidencial en 1938 a manos del Frente Popular, importante critical juncture, será un duro golpe para consolidar una hegemonía sobre los sectores populares, ya que los partidos y movimientos de izquierda al llegar al gobierno consolidan su relación e importancia en cuanto a bases de apoyo entre las clases bajas y obreras mediante organizaciones bastante institucionalizadas.

Debido a la repentina muerte en 1942 del Presidente Aguirre Cerda las elecciones presidenciales se adelantan y Carlos Ibáñez vuelve a competir, esta vez apoyado por la derecha (a través del Partido Conservador y el Partido Liberal) apelando a un populismo anticomunista que criticaba a la izquierda y su control sobre los trabajadores mediante los sindicatos. Sin embargo, nuevamente la estrategia populista de Ibáñez no logra concitar un apoyo mayoritario, con sectores conservadores y liberales (entre ellos el expresidente Arturo Alessandri) críticos de su pasado autoritario, por lo que es derrotado por el candidato del Frente Popular Juan Antonio Ríos.

\section{La tercera es la vencida: Ibáñez y su triunfal regreso en 1952}

A pesar de que Ibáñez en sus anteriores aventuras presidenciales utilizó fórmulas populistas en sus promesas de campañas, es en la campaña presidencial y posterior victoria en 1952 donde se aprecia con mejor claridad las características populistas al estilo "clásico" del militar chileno. Al igual que en sus pasadas aventuras electorales, en 1952 Ibáñez tuvo una base política de apoyo heterogénea y muy fragmentada aglutinada en torno a su figura personalista, siendo los dos principales partidos políticos que apoyarían a Ibáñez el Partido Agrario Laborista (PAL) y el Partido Socialista Popular (PSP). El elemento innovador en las bases de apoyo en esta elección fue el componente femenino ya que las mujeres en Chile obtuvieron el pleno derecho a sufragio en 1949, y en ese contexto fue que varias agrupaciones femeninas se sumaron a la candidatura de Ibáñez siendo la principal agrupación el Partido Femenino de Chile liderado por María de la Cruz, cuyo ideario se basaba en nacionalismo económico y el reformismo social a favor de los sectores más pobres (Fernández, 2007: 177), existiendo similitudes con el Peronismo argentino. A esto se le sumaban componentes propagandísticos similares a los usados por el Peronismo a la usanza de las 20 verdades peronistas. 
Ejemplo de esto fue el "Catecismo del Obrero Chileno" y el "Juramento de fe ibañista", donde se ofrecía castigar a los ladrones del Estado (en referencia a los políticos y partidos, especialmente del radicalismo) y especuladores (asociados a la oligarquía).

A diferencia de Perón que en 1946 cumplió el desafío de organizar sus bases de apoyo mediante la CGT (Confederación General del Trabajo), el Partido Justicialista y el Estado, Ibáñez llevó al extremo su postura anti partidos y rechazó crear un partido ibañista, ya que prefería que el apoyo se diera de manera directa sin intermediarios, coincidiendo con la mirada no institucionalizada de los populismos según Weyland (2001). Sin lugar a dudas el camino no tomado de cooptar al movimiento obrero fue un error de Ibáñez en su proyecto populista, ya que el sindicalismo es un pilar fundamental para sustentar un régimen populista siendo el mejor ejemplo de ello la CGT durante el gobierno de Perón. También afectó al liderazgo populista de Ibáñez la ausencia del elemento emocional, ya que el ex dictador chileno no supo aprovechar al máximo dicho recurso debido su parca personalidad, restando de este modo épica a los pocos sucesos heroicos que se podía atribuir, como lo fue su participación en el fin del período histórico conocido como la "República Parlamentaria".

\section{La Unidad Popular: ¿Salvador Allende como líder populista?}

Considerando la escasa "tradición" populista que ha tenido Chile en relación a otros países en Sudamérica, muchas veces autores como Michael Conniff (1999) han señalado al gobierno de Salvador Allende como populista. La pugna entre grupos marxistas revolucionarios con grupos institucionales y legalistas hizo que la Unidad Popular tuviera este doble discurso revolucionarioinstitucional, que también adquirió ciertos elementos populistas como el carácter social a modo de bandera de lucha, que se traducía en propuestas como reforma agraria, expansión de cobertura en salud, educación, pensiones y vivienda a los sectores más pobres. También hubo un fuerte discurso maniqueo y antagónico que instaló Allende y la Unidad Popular, lo cual se demuestra con mediciones discursivas que muestran a Allende como el presidente chileno con un mayor nivel de maniqueísmo según datos de Hawkins y Rovira (2013: 14). Tampoco hay que olvidar el elemento movilizador de masas que tuvo la Unidad Popular que se tradujo en grandes muestras de apoyo en las calles, algo característico que utilizan líderes populistas para demostrar el apoyo que tienen. 
Desde la perspectiva populista de los "caminos no tomados", la Unidad Popular subestimó la importancia de la paz social que fue alterada por las acciones de grupos más radicalizados dentro y fuera de la Colación. Allende en su estilo apegado a las reglas de la democracia liberal desechó un aspecto muy característico de los populismos: el importante rol de autoridad que tiene el líder por sobre sus bases de apoyo. Si Allende hubiera sido más autoritario y personalista, es probable que su gobierno hubiera sido diferente, logrando una mayor estabilidad y acercándose más al área de los populismos. Lo cierto es que esto no fue así, y la sociedad chilena vivió una experiencia con la Unidad Popular que se oponía por completo a los valores tradicionales de su cultura política ligada al orden, tranquilidad social y respeto a las autoridades. Como se señaló anteriormente, fueron estos valores en los que se amparan los militares (y los civiles que los apoyan) para derrocar a Allende en 1973 y que reafirmaron una cultura política orientada al orden.

\section{El Golpe de Estado de 1973 y el Chile Post Pinochet: La reafirmación de una cultura política orientada al orden.}

El legado institucional del Régimen de Pinochet buscó prevalecer los tradicionales valores asociados al orden y tranquilidad social debido a que por medio del sistema electoral binominal se generaron incentivos de gobernabilidad, estabilidad y consenso entre las distintas fuerzas políticas (Carey, 2006). Esto se suma a los altos quórums para reformar la Constitución de 1980 promulgada en el Gobierno Militar, situación que ha sido criticada ya que limitaría la soberanía popular para realizar cambios en el mismo sistema político institucional (Pastor, 2004).

Por otro lado, un segundo impacto del Régimen de Pinochet sobre la cultura política fue un trauma, en especial por parte de la izquierda, respecto a las fórmulas políticas movilizadoras y transgresoras, que utilizó la Unidad Popular y que tuvieron un trágico final. Tal como lo señala Judith Scheele (2010:34): "Los partidos de izquierda entienden ahora que las reformas sociales y económicas que se quieren implementar no puedan ser de carácter demasiado radical porque causan miedo e incertidumbre entre las demás clases sociales". El panorama político y social de Chile tras el fin de la dictadura, aunque fuertemente influenciado por su legado, reafirmó los valores de cultura política de orden y paz social que se expresó en 20 años de gobierno de una coalición de centro izquierda (Concertación) que mostró claros signos de moderación que contrastaban con la estrategia rupturista que previamente habían mostrado sectores de la izquierda chilena a fines de los años 60's (Grez, 2014). 


\section{CONCLUSIÓN}

La supuesta "excepcionalidad" de Chile que lo diferencia del resto de América del Sur encuentra su sustento en el hecho de que el país posee una especie de "inmunidad" frente al fenómeno populista. A nivel macro esta afirmación del Chile "excepcional" es verdad, ya que ninguno de los liderazgos populistas analizados alcanzó una relevancia tal como el de Perón en Argentina que tiene incidencia política hasta la actualidad en el sistema político argentino (Novaro, 2014).

Analizando en detalle ciertos períodos y personajes a lo largo de su historia, es posible encontrar ciertos "resabios" a nivel micro de populismo en Chile, los cuales sin embargo no prosperaron. De acuerdo al análisis realizado en este trabajo, vía la metodología histórica de los "caminos no tomados", Chile ha presentado una cultura política apegada al orden y las instituciones, que es particularmente hostil al populismo, ya que, a lo largo de su historia, cada critical junctures (coyuntura crítica) ha devenido en una vía institucional, por más que se haya querido evitar esa vía. Los ejemplos son varios, partiendo por Arturo Alessandri y su sumisión frente un congreso conservador, como también el caudillismo Grove que sucumbe ante la institucionalización del Partido Socialista. En los últimos años con la fuerte emergencia de movimientos sociales sumado a la deslegitimación institucional se pensó que esto podría derivar en un liderazgo populista y nada de ello ha ocurrido hasta ahora. Muy por el contrario, los dirigentes sociales entraron de lleno en la institucionalidad para desempeñarse como legisladores, tal como los casos de Camila Vallejo, quien fuera líder del movimiento estudiantil, o Iván Fuentes, que fue líder de las protestas regionales en Aysén.

No obstante, no hay que olvidar que la cultura política es susceptible de cambios producto de ciertos eventos que conmocionan a toda una sociedad y pueden modificar sus actitudes. Por lo mismo, es imposible decir que en Chile nunca florecerá el populismo, pese a que el país haya presentado desde sus orígenes una cultura política alejada de los valores populistas. Además, mientras en Chile siga existiendo un escenario de descrédito de partidos, clase política e instituciones, habrá motivos para preocuparse sobre el eventual nacimiento de liderazgos populistas. 


\section{REFERENCIAS}

ALMOND, Gabriel (1965): The civic culture: political attitudes and democracy in five nations: an analytic study G A. Almond, Sidney Verba. (Boston, Editorial Boston Little, Brown).

CAREY, John (2006): Las virtudes del sistema binominal.En Revista de ciencia política (Santiago), PUC, vol. 26, n 1, 226-235.

COLLER, Ruth y COLLER, David (2002): Shaping the Political Arena: Critical Junctures, the

Labor Movement, and Regime Dynamics in Latin America (Paris, University of Notre Dame Press).

CoNNIFF, Michael (1999): Populism in Latin America. (Tuscaloosa, University of Alabama Press).

Contreras, Gonzalo y NAVIA, Patricio (2013): "Diferencias Generacionales en la Participación Electoral en Chile, 1988-2012". En Revista de Ciencia Política, PUC, vol. 33, n² 2, pp 419-441.

CONTRERAS-AGURRE, Gonzalo, y MORALES-QUIROGA, Mauricio (2014): Jóvenes y participación electoral en Chile 1989- 2013. Analizando el efecto del voto voluntario. En Revista Latinoamericana de Ciencias Sociales, Niñez y Juventud, vol. 12, n², pp. 597-615.

DE LA TORRE, Carlos y ARNSON, Cynthia (2013): "Introduction: The Evolution of Latin American Populism and the Debates Over Its Meaning". En Latin American Populism in the Twenty-First Century, John Hopkins University Press, pp. 1-35.

DE LA TORRE, Carlos (1992): "The Ambiguous Meanings of Latin American Populisms". Social Research.

DRAKE, Paul. (1992): Socialismo y populismo: Chile 1936-1973. (Valparaíso, Instituto de Historia, Universidad Católica de Valparaíso).

DUARTE Villa, Rafael (2005): Venezuela: mudanças políticas na era Chávez. En Estudos Avançados, Universidade de Sao Paolo, vol. 19, n 55, pp. 153-172. FERNÁNDEZ, Joaquín (2007): El Ibañismo (1937-1952): un caso de populismo en la política chilena (Santiago de Chile, Pontificia Universidad Católica de Chile).

GARCÉS, Mario y RodRíGUEZ, María Angélica (2004): Participación social en Chile. Una visión histórica de la participación como conquista social y oferta estatal en Chile (Santiago de Chile, ECO, Educación y Comunicaciones).

GREZTOSO, Sergio. (2014): La izquierda chilena y las elecciones: una perspectiva histórica (1882-2013). En Cuadernos de historia, Universidad de Chile, vol. 40, pp. 61-93. HAWKINS, Kirk y RoviRA, Cristóbal (2013): "Populism as and Ideational Concept". Paper presentado en Asociación de Estudios Latinoamericanos (LASA). Washington DC, 29 de Mayo a 1 de junio de 2013. 
KNIGHT, Alan (1998): “Populism and Neo-populism in Latin America”. En Journal of Latin American Studies, University of Cambridge, vol. 30, $\mathrm{n}^{\circ} 2$, pp. 223- 248.

LACLAU, Ernesto (2005): La razón populista (Buenos Aires y México, FCE). Mellado CARRASCO, Vicente (2015): “iPor el derecho de asociación y de huelga!: La Federación Obrera de Chile (FOCH) y el camino a la legislación laboral (19211924)". En Cuadernos de historia, Universidad de Chile, vol. 42, pp. 85-125 MouLí́n, Tomás (1995): “Chile: las condiciones de la democracia”. En Nueva Sociedad, Volumen 140.

MudDE, Cas y RoviRA Kaltwasser, Cristobal (2012): “Populism and (Liberal) Democracy: a Framework for Analysis." En Mudde y Rovira, (comp.): Populism in Europe and the Americas. (Cambridge, Cambridge University Press).

NovARO, Marcos (comp.). (2014): Peronismo y democracia. Historia y perspectivas de una relación compleja (Buenos Aires, Edhasa).

SCHEELE, Judith (2010): “Entre orden y caos: La formación de una cultura política chilena desde una perspectiva histórica". En Revista Pléyade, Centro de Análisis e Investigación Política de Chile, vol. 5, pp. 1-44.

OstiguY, Pierre (2013): "Flaunting the "Low" in Politics: A Cultural-Relational Approach to Populism". En Taggart et al (Eds.): The Oxford Handbook of Populism (Oxford, Oxford University Press).

PANIZZA, Francisco (2005): "Introduction: populism and the mirror of democracy" In: Panizza, Francesco, (ed.) Populism and the Mirror of Democracy. Verso Books.

PASTOR, Daniel (2004). Origins of the Chilean Binominal Election System. En Revista de Ciencia Política, PUC, vol. 24, n²1, pp. 38-57.

RAMÍREZ, Jorge, y BRAVO, Nicolás. (2014). "Movimientos Sociales en Chile: Una Radiografía al Proceso de Movilización 2009-2014". En Serie Informe Sociedad y Política, Libertad y Desarrollo, Libertad y Desarrollo, vol. 144, pp. 1-44.

WeYLAND, Kurt (2001): "Clarifying a Contested Concept: Populism in the Study of Latin American Politics.» Comparative Politics, University of New York, vol. 34, nº 1.

WIARDA, Howard (2001): The soul of Latin America: the cultural and political tradition (New Haven, Yale University Press). 


\section{PRENSA}

Ercilla (Santiago de Chile), 11 de noviembre de 1952

La Escoba (Santiago de Chile), 3 de septiembre de 1952

La Opinión (Santiago de Chile), 15 de octubre de 1932

La Opinión (Santiago de Chile), 20 de junio de 1938 